\title{
An interview with...
}

\author{
Guglielmo Cinque \\ Ca'Foscari University, Venice
}

Guglielmo Cinque is an emeritus professor at Ca' Foscari University in Venice. He is one of the leading figures in generative syntax, and the most prominent representative of generative syntactic typology. $\mathrm{He}$ is one of the founders of the cartographic enterprise.

His publications include Typological Studies. Word Order and Relative Clauses (2013, Routledge), The Syntax of Adjectives. A Comparative Study (2010, MIT Press), Restructuring and Functional Heads. The Cartography of Syntactic Structures (2006, OUP), Adverbs and Functional Heads. A Cross-Linguistic Perspective (1999, OUP), Italian Syntax and Universal Grammar (1995, CUP), Types of $\bar{A}$-dependencies (1990, MIT Press). He has published extensively on every aspect of Italian syntax and syntax in general.

Isogloss: From your perspective, what are the relevant levels of abstractness to approach the faculty of language? The standard ones (namely "language," "dialect," and "idiolect")? Others?

GC: The relevant level of abstractness to approach the Faculty of Language (or Universal Grammar (UG)), is Noam Chomsky's notion of I-language ("I" for internal, individual, and intensional - Chomsky 1986 and subsequent work), which ultimately coincides with idiolect, or rather I-idiolect. In the best cases what we do is study and try to rationally reconstruct the system underlying our own idiolect, and compare it with the idiolects of others. "Dialect" and "language" are convenient idealizations for clusters of I-idiolects that happen to share most properties (perhaps never all properties). "Dialect" is often used to refer to a cluster of I-idiolects that share more common properties than those characterizing a "language", but there is really no principled reason, other than that, to distinguish "dialect" from "language" (in syntony with Max Weinreich's famous definition "A language is a dialect with an army and navy"). Comparisons between "different languages", say Italian and Paduan, or Italian and French, or English and Japanese involve comparisons between 
clusters of I-idiolects that share fewer (and fewer) common properties (within severe limits to variation).

\section{Isogloss: What are the main advantages / reasons to study linguistic variation?}

GC: The study of linguistic variation is an essential part of the effort to reconstruct UG, not only to have a more precise idea of what can vary and what cannot (i.e., the limits of the variation allowed by UG), but also, as Richard Kayne has shown in his work and has stressed explicitly, "to exploit those differences as a new and often exciting source of evidence bearing on the characterization and delineation of the principles of UG" (Kayne 2005: 3). Within a Minimalist perspective (Chomsky 1995 and subsequent work), one of the challenges we are confronted with is whether all or most variation can be reduced to different movement options and to differences in pronunciation/non-pronunciation of functional elements encoded in the lexicon (cf. Rizzi 2009, 2011), a question I come back to.

Isogloss: How do you conceive the relation / tension between linguistic variation and linguistic uniformity throughout the years?

I still think the Principles and Parameters approach that emerged in the late ' 70 's is the best model to resolve the tension between linguistic variation and linguistic uniformity, even if our current conception of the principles and especially of the parameters that make up UG may have changed; a point I briefly return below.

Isogloss: In your opinion, what are the contributions of dialectology (both traditional and present-day studies) to the study of language?

GC: As Benincà (1994) and Kayne (2005: 8) have pointed out, the important contribution of dialectology, understood as a comparative investigation of closely related language varieties, is the fact that it is the closest we can get to a controlled experiment in comparative syntax (much as variation in the biological world comes close to constitute a controlled experiment in a domain where real experiments cannot be carried out without destroying the objects to be studied).

Isogloss: What are the relevant sources to obtain evidence to study language and its variation (speakers' own competence, corpora, experiments, nonlinguistic disciplines, etc.)? Is any of them potentially more relevant than the others?

GC: While there should in principle be no preclusion to the kind of evidence one can use to deepen our understanding of language, in my mind one type of evidence has a privileged status in representing a more reliable source of data: the judgments a linguist can produce concerning his or her own native language. Of course, even this gives no protection from errors nor guarantee of success, but is perhaps the best 
approximation to the ideal experimental setting. In many cases we have to make do with less reliable sources, such as grammatical descriptions or analyses of single topics of languages that are not native to the linguists describing or analyzing them, so that any conclusion based on these must be treated with caution and subjected to further control whenever possible. In spite of that, even this kind of sources may offer insights, at least in certain areas of grammar (as the tradition stemming from Joseph Greenberg's work has shown).

Isogloss: Much current theoretical research is complemented with corpora and statistical / experimental analyses. In fact, dialectology also resorts to experimental and field work methods, traditionally. What do you think is the position of theoretical approaches to language in such scenario?

GC: Theoretical approaches to language have much to gain from traditional methods of dialect data gathering, like questionaires and field work by specialists, as the recent advances in comparative syntax within both traditional and theoretically informed dialectology have demonstrated (see again Benincà 1994 and the remarks in Kayne 2001). More recently, experimental/statistical analyses of dialect data are also yielding new and significant insights for the theoretical treatment of specific syntactic phenomena, like the possible variation of verb clusters in Dutch dialects recently studied by Jeroen van Craenenbroeck (2014).

Isogloss: Part of your own work has been devoted to the study of universals. Different phenomena fall within such label, from hierarchies (as in your 1999 monograph) to categories. Are all of these phenomena "universals" in the same sense? Is there any type of universal that has cognitive (or grammatical) priority over the others?

The search for universals of language may take many different forms and I do not think there is any that has cognitive or grammatical priority over others. With respect to Chomsky's (1965: 29) distinction between formal and substantive universals, I have myself been more concerned with the second type, an inclination induced in part by the conviction that we still have to uncover many building blocks of UG. My own feeling is that the recent trend to impoverish the content of UG underestimates the domain-specificity of many aspects of grammar. The nagging question is: why do we find only certain distinctions, and the same ones, encoded grammatically in language after language (Cinque 2013a), sometime (as with numeral classifiers) in ways that are not immediately obvious (cf. Kayne 2003 and Cinque 2006)? Identity is often hidden.

It is certain that the hierarchies that have so far been proposed and the categories that are currently taken to be universal are approximations in need of amendment. Most probably the appropriate level of abstraction to capture the correct generalizations and to account for the attested cross-linguistic variation is more fine-grained (which means that the elements now being assumed will have to be further decomposed). 
Isogloss: Some recent studies argue that it is diversity what truly characterizes human language, often implying that the universal nature of language is wrong (or that some allegedly specific traits, such as recursion, is not present in all languages). Is this scenario a residue of the fact that the I-language / E-language distinction has not been understood? Is it something else?

GC: In many domains we tend to concentrate on what differentiates one token of a type from another rather than on what all of the tokens have in common. To take a well-known case, when we use our face recognition capacity, we are more prone to note what differentiates one face from another (with distinctive social advantages) rather than what is common to each. Much the same has happened (and is still happening) with language. The earliest reflections on language (and, with some notable exceptions, all subsequent theorizing until the cognitive revolution of the second half of last century) concentrated on the existence of different languages or on different stages of the "same" language, rather than on what languages have in common. This bias persists to the present day (in the work you are alluding to). It's as if one were to say that it is "diversity what truly characterizes humans" (after all there are no two identical humans), but this would clearly miss the fundamental identity, at some level, of the individuals of our species. The same appears true of language. Not only specific traits like recursion (see Hauser, Chomsky and Fitch 2002, and Legate, Pesetsky and Yang's 2014 recent response to Levinson 2013) may be a domain-specific property of language; many more things are found in language after language, which may be domain-specific. It is striking for example that every (reasonably described) language is reported to have in its nominal phrase demonstratives, quantifiers, numerals, diminutives, special functional adjectives like 'other', etc. (if there are minor morphological differences these depend on independent properties of the languages in question, like the presence of morphological Case, agreement, or other morphophonological idiosyncracies). The domain-specificity of these categories remains an open question, but is possibly supported by the already mentioned observation that of all the cognitive distinctions that one could expect to be grammatically encoded in a nominal phrase, one keeps finding the same few ones (cf. Cinque 2013a). The objection that they presumably reflect non linguistic capacities is beside the point (why those and not others?). Their being possible reflections of more general cognitive properties does not exclude their being domain-specific, i.e. their belonging to the substantive part of UG.

Isogloss: Within the Generative Enterprise, the research stemming from the Principles and Parameters framework has proven very fruitful to study both variation and uniformity. However, this trend has been subject to much criticism, on both theoretical and empirical grounds. In your opinion, what is the status of "Parameter Theory" nowadays?

GC: My feeling is that there is no escape from parameters, but surely many questions remain open. What is a possible parameter? Are there parameterized principles? Where is the locus of parameters (narrow syntax, the lexicon, the PF interface, outside of UG)? Many differences between languages are possibly the 
consequence of the interplay of different (relatively small) parameters rather than of single large scale parameters. A possible example of this is the original Null Subject parameter (Rizzi 1982), which has been decomposed into finer-grained components (cf., e.g., Nicolis 2008, also referring to Rizzi's subsequent work). UG principles (Merge, the Linear Correspondence Axiom (LCA), Criterial Freezing, etc.) are plausibly not parameterized, and neither are, possibly, the functional hierarchies of the clause and of its phrases. While many (perhaps most) parameters may be directly encoded in items of the lexicon (Kayne 2005, Rizzi 2009, 2011), my feeling is that some may still belong to narrow syntax. Take the traditional "word order parameter". If (as dictated by the LCA) linear order is a function of hierarchical structure and if "head-initial" and "head-final" languages involve non symmetrical hierarchical structure derived by different types of movements, then part of the parameter is how (internal) Merge operates in narrow syntax. The parameter cannot be entirely a matter of externalization (at the PF interface). Equally, it cannot simply be the effect of the accumulation of many lexically encoded instructions. While this is plausible for cases of non consistency, in which a single (functional or substantive) lexical item deviates from the general "head-initial" or "head-final"pattern, the same does not seem plausible for the more consistent cases.

\section{Isogloss: What are the challenges that we will have to address in the following decades when it comes to study language and its variation?}

GC: To my mind, two questions that remain to be addressed and hopefully to be better understood in the next future concern word order (how to analyze attested and unattested word order variations across languages) and the lexicon (the notion of "possible word" and how to handle apparent lexical differences among languages).

Concerning the first issue, although one can make out the existence of a great underlying ground plan governing the order of clausal and phrasal elements in the languages of the world (approximately, the "head-initial" and "head-final" organization of linear order - cf. Cinque 2013b, Chapter 1) the degree of differences, and inconsistences, is bewildering. What is even more baffling is the fact that the different canonical word orders that one finds (or the hierarchical differences at their basis) look like "noise", in the sense that they serve no semantic or pragmatic purpose (why should some "head-initial" language say "he can swim well" and some "head-final" one "he well swim can" to convey the same thought?).

Concerning the lexicon, the traditional idea that it is essentially a repository of idiosyncrasies may in fact hide much more structure and systematicity. In my view, a promising syntactic approach to apparent lexical differences among languages or what look like accidental gaps in some language as opposed to another is the one suggested in Kayne $(2008,2012$ ) (see also Cinque to appear on some related questions). 


\section{References}

Benincà, Paola (1994) La variazione sintattica: Studi di dialettologia romanza. Bologna: Il Mulino.

Chomsky, Noam (1965) Aspects of the Theory of Syntax. Cambridge, Mass.: MIT Press.

Chomsky, Noam (1986) Knowledge of Language. Its Nature, Origin and Use. New York: Praeger.

Chomsky, Noam (1995) The Minimalist Program. Cambridge, Mass.: MIT Press.

Cinque, Guglielmo (2006) Are all languages 'Numeral Classifier Languages'? $\begin{array}{llll}\text { Rivista di grammatica } & \text { generativa }\end{array}$ http://arca.unive.it/handle/10278/2490

Cinque, Guglielmo (2013a) Cognition, Universal Grammar, and typological generalizations. Lingua 130.50-65

Cinque, Guglielmo (2013b) Typological Studies. Word Order and Relative Clauses. London: Routledge.

Cinque, Guglielmo (to appear) A Source of Parametric Variation in the Lexicon. In A.Gallego and D.Ott, eds., Aspects' 50th Anniversary. MIT Working Papers in Linguistics.

Craenenbroeck, Jeroen (2014) In search of microparameters: a quantitative approach. Workshop 'What happened to Principles and Parameters?', Villa Salmi, Arezzo. July 3-5 2014

Hauser, Marc D.; Noam Chomsky; and W. Tecumseh Fitch. 2002. The faculty of language: What is it, who has it, and how did it evolve? Science 298.1569-79.

Kayne, Richard S. (2001) "Review of Paola Benincà La variazione sintattica: Studi di dialettologia romanza, Il Mulino, Bologna (1994)," Romance Philology, 54.492-499 (also in R.S.K. Movement and Silence. New York: Oxford University Press, (2005), 57-64).

Kayne, Richard S. (2003) Silent years, silent hours. In L.-O.Delsing, C.Falk and G. Josefsson, and H. Sigurðsson, eds., Grammar in Focus: Festschrift for Christer Platzack, eds., Oslo: Novus. (also in R.S.K. Movement and Silence. New York: Oxford University Press, (2005), pp. ).

Kayne, Richard S. (2005) Some Notes on Comparative Syntax: With Special Reference to English and French. In G. Cinque and R. S. Kayne, eds. Handbook 
of Comparative Syntax, New York: Oxford University Press, 3-69. (also in R.S.K. Movement and Silence. New York: Oxford University Press, (2005), pp.277-333).

Kayne, Richard S. (2008) Comparative Syntax and the Lexicon. In J. Durand, B. Habert and B. Laks (eds.) Congrès Mondial de Linguistique Française CMLF'08, Paris, 2008, Institut de Linguistique Française. http://www.linguistiquefrancaise.org/index.php?option=com_article\&access=stan dard\&Itemid=129\&url=/articles/cmlf/pdf/2008/01/cmlf08350.pdf

Kayne, Richard S. (2012) Comparative Syntax and English Is To. To appear in Linguistic Analysis. http://linguistics.as.nyu.edu/docs/IO/2652/Kayne1112IsTo.pdf

Legate, Julie Anne; David Pesetsky; and Charles Yang (2014) Recursive misrepresentations: A reply to Levinson (2013) Language 90.515-528

Levinson, Stephen C. 2013. Recursion in pragmatics. Language 89.149-62

Nicolis, Marco (2008) The Null Subject Parameter and correlating properties: the case of Creole languages. In T.Biberauer, ed., The Limits of Syntactic Variation. 271-294. Amsterdam: Benjamins.

Rizzi, Luigi (1982) Issues in Italian Syntax. Dordrecht: Foris.

Rizzi, Luigi (2009) Some elements of syntactic computation. In D.Bickerton and E.Szathmáry, eds., Biological Foundations and Origin of Syntax. 63-88. Cambridge, Mass.: MIT Press.

Rizzi, Luigi (2011) The Elements of Variation: format, locus and acquisition of parametric properties. Talk given at 50 Years of Linguistics at MIT, 9 Dec. 2011. http://www.youtube.com/watch?v=dXHSR_qpCEM 